\title{
Atherogenic $\omega$-6 Lipids Modulate PPAR- EGR-1 Crosstalk in Vascular Cells
}

\author{
Jia Fei, ${ }^{1}$ Carla Cook, ${ }^{1}$ Miriah Gillespie, ${ }^{1}$ Bangning Yu, ${ }^{2}$ Khyra Fullen, ${ }^{1}$ and Nalini Santanam ${ }^{1}$ \\ ${ }^{1}$ Department of Pharmacology, Physiology and Toxicology, Joan C. Edwards School of Medicine, Marshall University, \\ Huntington, WV 25755, USA \\ ${ }^{2}$ Department of Pharmacology and Experimental Therapeutics, LSU Health Sciences Center, New Orleans, LA, USA
}

Correspondence should be addressed to Nalini Santanam, santanam@marshall.edu

Received 30 April 2011; Revised 17 June 2011; Accepted 11 July 2011

Academic Editor: R. P. Phipps

Copyright () 2011 Jia Fei et al. This is an open access article distributed under the Creative Commons Attribution License, which permits unrestricted use, distribution, and reproduction in any medium, provided the original work is properly cited.

\begin{abstract}
Atherogenic $\omega$-6 lipids are physiological ligands of peroxisome proliferator-activated receptors (PPARs) and elicit pro- and antiatherogenic responses in vascular cells. The objective of this study was to investigate if $\omega$ - 6 lipids modulated the early growth response-1 (Egr-1)/PPAR crosstalk thereby altering vascular function. Rat aortic smooth muscle cells (RASMCs) were exposed to $\omega$-6 lipids, linoleic acid (LA), or its oxidized form, 13-HPODE (OxLA) in the presence or absence of a PPAR $\alpha$ antagonist (MK886) or PPAR $y$ antagonist (GW9662) or PPAR-specific siRNA. Our results demonstrate that $\omega$-6 lipids, induced Egr-1 and monocyte chemotactic protein-1 (MCP-1) mRNA and protein levels at the acute phase (1-4 hrs) when PPAR $\alpha$ was downregulated and at subacute phase (4-12 hrs) by modulating PPAR $\gamma$, thus resulting in altered monocyte adhesion to RASMCs. We provide novel insights into the mechanism of action of $\omega-6$ lipids on Egr-1/PPAR interactions in vascular cells and their potential in altering vascular function.
\end{abstract}

\section{Introduction}

Early growth-response (Egr-1) is a critical mediator of vascular pathology by activating its dependent genes, tumor necrosis factor- $\alpha(\mathrm{TNF} \alpha)$ (a potential stimulator of nuclear factor kappa B-NF $\kappa$ B) and monocyte chemotactic protein-1 (MCP-1) [1-4]. MCP-1 has a specific Egr-1 binding element in its promoter region and is therefore directly activated by Egr-1 $[5,6]$. Many of these target genes in turn activate Egr-1 by a positive feedback mechanism and thereby further amplifying their effects [7].

Peroxisome proliferator-activated receptors (PPAR $\alpha, \beta$, $\gamma)$ are transcription factors that regulate various cellular processes including lipid and glucose homeostasis $[8,9]$. Both PPAR $\alpha$ and PPAR $\gamma$ are expressed in vascular cells including endothelial cells, smooth muscle cells (vSMCs), and monocyte/macrophages $[10,11]$. Activators of PPARs have beneficial effects against atherosclerosis $[12,13]$. Ligandmediated activation of PPAR $\alpha$ [14-17] and PPAR $\gamma$ attenuates the release of inflammatory factors including the production of monocyte chemotactic protein-1 $[18,19]$. Interestingly,
PPARs can directly interact with Egr-1 and attenuate its downstream effects [20]. This attenuation is effective by the activation of both PPAR isotypes, PPAR $\alpha$ [21] and PPAR $y$ [22]. However, in vascular cells there exists a timedependent crosstalk between Egr-1 and PPARs, for example, Egr-1 exhibits a critical early stimulatory effect but a later inhibitory effect on PPARs [23].

Atherogenic $\omega$-6 lipids such as linoleic acid (LA, $18: 2 n-$ 6) and its oxidized forms, 13-hydroperoxy octadecadienoic acid (13-HPODE) and 13-hydroxyoctadecadienoic acid (13HODE) are physiological ligands for both PPAR $\alpha$ [24] and PPAR $y$ [25-28], that can covalently interact with PPARs and alter their activity $[29,30]$. The biological significance of these interactions is not well understood. LA is the predominant polyunsaturated fatty acid found in the Western diet [31], which at lower doses has lipid-lowering beneficial effects [32], but, deleterious effects when consumed in excess [33]. Oxidized forms of LA (oxidized linoleic acid (OxLA)) and other oxidized $\omega-6$ lipids are present in significant amounts in heated oils and processed foods [34-37]. $\omega-6$ lipids are also major components of oxidized low-density 


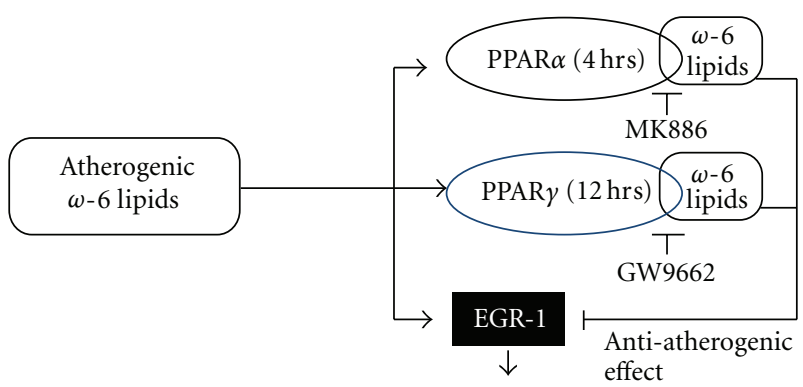

Pro-atherogenic effect

Scheme 1: Atherogenic $\omega-6$ lipids modulate PPAR-Egr-1 crosstalk. A schematic representation of a possible mechanism by which $\omega$ 6 lipids and their oxidized forms regulate PPAR-Egr-1 crosstalk in a time-mediated fashion and thereby altering smooth muscle cell function. $\omega-6$ lipids seemed to have a time-dependent modulation of PPAR isotypes, PPAR $\alpha$ at acute phase and PPAR $\gamma$ at subacute phase. This modulation of PPAR isotype altered the ability of these lipids to exert an antiatherogenic effects via PPARs or proatherogenic effects via Egr-1.

lipoproteins (Ox-LDLs) that exhibit both pro- and antiatherogenic effects on vascular cells [38-40].

Since Egr-1 regulates the proinflammatory and PPARs regulates the anti-inflammatory pathways in vascular cells, and that atherogenic $\omega-6$ lipids interact with both these transcription factors, we speculate that these lipids could influence the crosstalk between these two transcription factors in a time- and concentration-dependent manner (Scheme 1) and thereby influence atherogenic events. In this study, the ability of LA and OxLA ( $\omega-6$ lipids that are abundant in dietary sources and OxLDL) to influence Egr-1 and PPAR crosstalk was investigated in primary rat aortic smooth muscle cells (RASMCs) in the presence or absence of known PPAR antagonists or by knocking down PPARs by siRNA approach. To our knowledge this is the first study that has investigated the ability of atherogenic $\omega$ 6 lipids to modulate EGR-1-PPAR crosstalk. Our findings will provide insights into the biological significance of the interactions between physiological ligands of PPAR and other transcription factors.

\section{Materials and Methods}

2.1. Materials. Dimethylsulfoxide (DMSO), PPAR $y$ antagonist (GW9662) was obtained from Invitrogen (Carlsbad, CA). PPAR $\alpha$ antagonist (MK886) was obtained from Cayman (Ann Arbor, MI). Linoleic acid and soybean lipoxidase were obtained from Sigma (St. Louis, MO). Rabbit Egr-1 and MCP-1 monoclonal antibody was obtained from Abcam (Cambridge, MA). Rabbit anti-actin monoclonal antibody was obtained from Sigma (St. Louis, MO). PPRE-luciferase construct $\left[\mathrm{p}\left(\mathrm{AOX}_{3}\right)-\mathrm{TKSL}\right]$ was a gift (Dr. Richard Niles, Marshall University, Huntington, WV).

2.2. Oxidation of Linoleic Acid. A $10 \mathrm{mM}$ stock solution of linoleic acid (LA-18:2) was first prepared in absolute ethanol which was further diluted in phosphate-buffered saline (PBS) to make $0.1 \mathrm{mM}$ LA solution. A fresh aliquot of $0.1 \mathrm{mM}$ LA solution was oxidized with soybean lipoxidase (100$200 \mathrm{U} / 100 \mathrm{nmol}, 1 \mathrm{hr}$ at $37^{\circ} \mathrm{C}$ ) to generate oxidized linoleic acid (OxLA-13-HPODE and 13-HODE) [41]. The conversion of LA to OxLA (HPODE or HODE) was monitored spectrophotometrically (Shimadzu, Columbia, MD) as an increase in the absorbance at optical density of $234 \mathrm{~nm}$. Usually, $>98 \%$ of unoxidized LA was converted to OxLA.

2.3. Cell Treatment and Sample Collection. Primary rat aortic smooth muscle cells (RASMCs) were cultured in specific growth media following the recommendations of the manufacturer (ATCC, Manassas, VA) and used at a passage number below 15 . Unless otherwise indicated, $70-80 \%$ quiescent cells were first pretreated with GW9662 $(1 \mu \mathrm{M})$, MK886 $(10 \mu \mathrm{M})$ or DMSO $(1 \mu \mathrm{M})$ (vehicle) for 2 hours. Pretreated cells were then exposed to either LA or OxLA at 10, 25 and $50 \mu \mathrm{M}$ concentrations, for $0,1,4$, or 12 hours (hrs). The control (CTRL) was defined as cells treated with vehicle alone (DMSO). Each treatment was run in duplicates and one set of cells were used for qRT-PCR analyses and the second set was used for Western blotting. Each experiment was repeated at least three times.

2.4. siRNA Transfection. RASMCs were cultured to $50-70 \%$ confluence and then transfected using $50 \mathrm{nmoles}$ of a pooled mixture of ON-TARGETplus SMARTpool siRNA duplexes (SMARTpool, Thermo Scientific Dharmacon, Lafayette, CO) for PPAR $\alpha, \operatorname{PPAR} \gamma$ or a nonspecific control siRNA (Nontargeting pool, Thermo Scientific Dharmacon, Lafayette, CO) using Thermo Scientific DharmaFECT transfection reagents and siRNA transfection protocol (Thermo Scientific Dharmacon, Lafayette, CO). Forty eight hours after transfection, quiesced cells were treated with vehicle (CTRL), 25 and $50 \mu \mathrm{M} \mathrm{LA}$, and 10,25 and $50 \mu \mathrm{M}$ OxLA for either 4 or 12 hours. Egr-1 mRNA levels were determined after each treatment by real-time PCR.

2.5. Quantitative Real-Time Reverse-Transcriptase PCR ( $q R T$ $P C R)$. Total RNA was extracted from the treated cells using the TRIzol reagent kit (Sigma, St-Louis, MO) according to the manufacturer's protocol. The mRNA levels of Egr-1 and MCP-1 were analyzed in a MyiQ real time PCR system (Bio-Rad, Hercules, CA). $\beta$-actin was used as the house-keeping gene. The real-time PCR was carried out in $25 \mu \mathrm{L}$ of a SYBR green reaction mixture containing $1 \mu \mathrm{L}$ of cDNA and iQ SYBR Green Supermix (Bio-Rad, Hercules, CA) containing the respective primers: Egr-1 (NM_012551) 5'-aacactttgtggcctgaacc$3^{\prime}, 3^{\prime}$-aggcagaggaagacgatgaa- $5^{\prime}$; MCP-1 (NM_031530) $5^{\prime}-$ atgcagttaatgccccactc- $3^{\prime}, \quad 3^{\prime}$-ttccttattggggtcagcac- $5^{\prime} ; \quad \beta$-actin was used as the house-keeping control (NM_031144) $5^{\prime}$-gtccacccgcgagtacaacct- $3^{\prime}, 3^{\prime}$-tcgacgacgagcgcagcgata-5'. A sequence detection program calculated a threshold cycle number (CT) at which the probe cleavage-generated fluorescence exceeded the background signal [42]. The realtime PCR results were expressed as fold change \pm Standard Error of $\Delta \mathrm{Ct}$ for each group compared to control (vehicle 
treatment) after normalizing to beta actin (housekeeping gene) using the Pfaffl method $\left(2^{-\Delta \Delta \mathrm{Ct}}\right)[42]$.

2.6. Western Blot Analysis. For Western blotting, the treated cells were rinsed in phenol-red free Hanks buffer and whole cell lysates were prepared in RIPA buffer (TRIS $50 \mathrm{mM}$, sodium chloride $150 \mathrm{mM}$, Triton $1 \%$, sodium deoxycholate $1 \%$, SDS $0.1 \%$, EDTA $5 \mathrm{mM}$ ) containing protease inhibitors (Roche Diagnostics, Indianapolis, IN). Total protein in the cell lysates was quantified using the Lowry method [43]. Equal amount of the cell proteins were subjected to SDSPAGE. After transfer, blots were probed individually with a solution of rabbit antibody to rat Egr-1 $(1: 3000)$, MCP$1(1: 7000), \operatorname{PPAR} \alpha(1: 2000), \operatorname{PPAR} \gamma(1: 7000)$, or $\beta$-actin $(1: 1000)$ as housekeeping protein and then analyzed using the chemiluminescence detection method (Millipore, Billerica, MA). The protein levels were quantified by densitometry of the respective bands on the autoradiograph (Bio-Rad, Hercules, CA). The results were expressed as the ratio of protein levels in treated samples compared to CTRL after normalizing to $\beta$-actin.

2.7. Transient Transfection and Luciferase Reporter Assay. RASMCs in 12-well plates (50,000 cells per well) were transfected with $0.5 \mu \mathrm{g}$ per well of the PPRE-luciferase construct ( $\mathrm{p}$ (A-OX3)-TKSL) using Lipofectamine-2000 transfection reagent (Promega, Madison, WI). After $24 \mathrm{hrs}$ of transfection, cells were transferred to serum-free EMEM media containing $1 \%$ charcoal stripped fetal bovine serum and either pretreated or untreated with PPAR antagonists, [MK886 $(10 \mu \mathrm{M})$ or GW9662 $(1 \mu \mathrm{M})]$. Following pretreatment, the cells were exposed for $4 \mathrm{hrs}$ with either LA or OxLA at 10, $25,50 \mu \mathrm{M}$ concentrations. Controls (CTRL) were defined as samples without LA or OxLA treatment. At the end of lipid treatment, the cells were washed in PBS three times and solubilized in 1X lysis buffer (Roche, Indianapolis, IN). PPRE transactivity was determined in the cell lysates by assaying for firefly luciferase activities using the Luciferase Reporter Assay System (Berthold, Germany). Each experiment was performed in duplicates and repeated three times. The results were expressed as the ratio of relative luciferase units (RLU) in treated samples/CTRL values.

2.8. Monocyte Adhesion Assay. To demonstrate the physiological consequences of alterations in Egr-1/MCP-1 levels by $\omega-6$ lipids on vascular function, monocyte adhesion studies were performed using established protocols [44]. Briefly, RASMCs were seeded in 12-well plates at a cell density of $1 \times 10^{5}$ cells/well. Once the cells reached 70 $80 \%$ confluence, it was exposed to $10-50 \mu \mathrm{M}$ concentrations of LA or OxLA with or without pretreatment to PPAR antagonists, MK886 $(10 \mu \mathrm{M})$ or GW9662 $(1 \mu \mathrm{M})$. At the end of 4 or 12 hours of lipid treatment, RASMCs were rinsed with Hanks balanced salt solution (HBSS) followed by the addition of $5 \times 10^{4} \mathrm{cells} / \mathrm{cm}^{2}$ THP1 (human monocytes) to each well. After 24 hrs coculture of RASMC and THP1, the plates were rinsed three times with PBS and adhered monocytes were counted in a $3 \times 3$ field under an inverted microscope (Leica-DMI4000B, Wetzlar, Germany) for each condition and duration of treatment. The average number of adhered monocytes for each treatment and time duration were counted by two independent investigators.

2.9. Statistical Analysis. The real-time PCR results were expressed as fold change \pm Standard Error of $\Delta \mathrm{Ct}$ for each group compared to control using the Pfaffl method ( $\left.2^{-\Delta \Delta \mathrm{Ct}}\right)$ [42]. All statistics were performed at the $\Delta \mathrm{Ct}$ stage in order to exclude potential bias due to averaging of data transformed through the equation $2^{\wedge-(\Delta \Delta C t)}[45]$. One way ANOVA was used for the comparison between two treatments at each time point. Vehicle control of the baseline (no antagonist pretreatment) group was used as the control for all statistical comparisons. Differences due to treatments in the density of the protein bands after Western blotting and the number of attached THP1 monocytes were analyzed for significance by one-way ANOVA, compared to the untreated, vehicle control. The relative data was presented as mean \pm Standard Error of mean. Significance was confirmed using post hoc analysis using Fisher's least significant difference (Fisher's LSD) test. A $P<0.05$ was considered statistically significant. In the figures, significant differences between vehicle control and treated samples is indicated as an asterisk-*, whereas significant difference between the lowest concentration to higher concentrations of the lipid treatments is indicated as “\#”.

\section{Results}

3.1. $\omega-6$ Lipids Modulate PPAR Protein Levels and Transactivity. PPARs are transcription factors, which upon ligand activation, promote regulation of genes that exhibit PPAR response elements $[46,47]$. The PPAR ligands regulate these transcription factors at the protein level. In RASMCs, LA and OxLA had a differential induction of PPAR subtypes, with an induction of PPAR $\alpha$ protein in the acute phase (1$4 \mathrm{hrs}$ ) (Figure 1(a)) and induction of PPAR $y$ at the subacute phase (12 hrs) (Figure 1(b)) compared to vehicle CTRL. The OxLA at increasing concentrations had 2-4-fold higher induction of PPAR $\alpha$ protein at $4 \mathrm{hrs}$ but less than baseline levels at $12 \mathrm{hrs}$. In contrast, OxLA was less effective on PPAR $y$ protein, with an induction of only about 2 -fold at 12 hrs.

PPAR transactivity studies using RASMCs transfected with PPRE-luciferase constructs showed that compared to vehicle CTRL, both LA and OxLA induced PPRE transactivity in a concentration-dependent manner, (Figure 1(c)). Pretreatment of the cells with a PPAR $\alpha$ antagonist MK886, exhibited a significant attenuation of the PPRE activity that was induced at all concentrations of LA and OxLA $(-81 \%$ for LA and $-50-80 \%$ for OxLA $)(P<0.005)$ after $4 \mathrm{hrs}$ treatment. On the contrary, pretreatment with PPAR $y$ antagonist, GW9662 only partially inhibited the PPRE transactivity induced by LA and OxLA $(-17 \%$ for LA and $-3-17 \%$ for OxLA), (Figure 1(c)). These results suggest a time-dependent modulation of PPAR subtypes by $\omega-6$ lipids. 


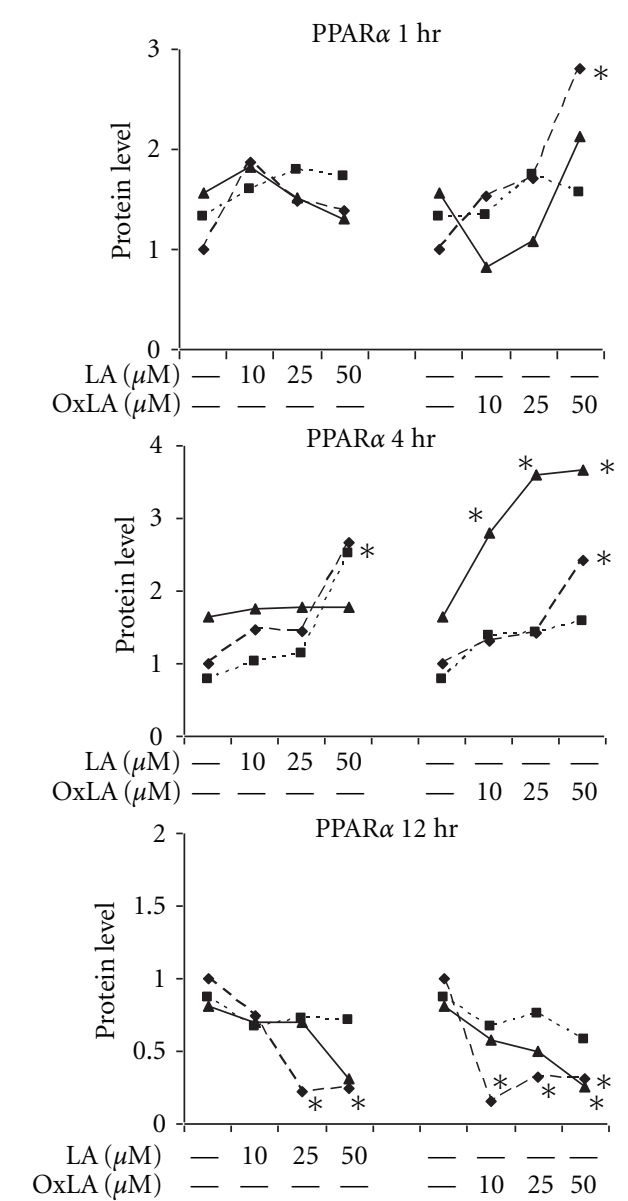

(a)

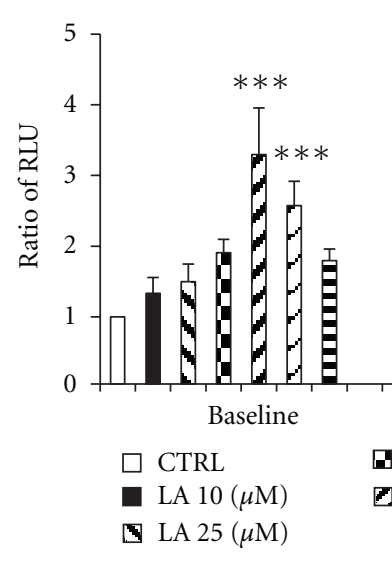

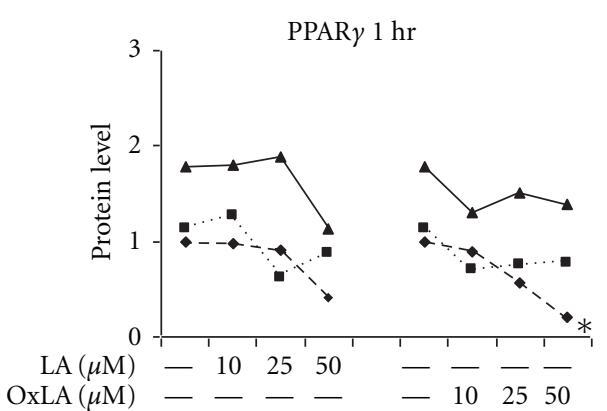
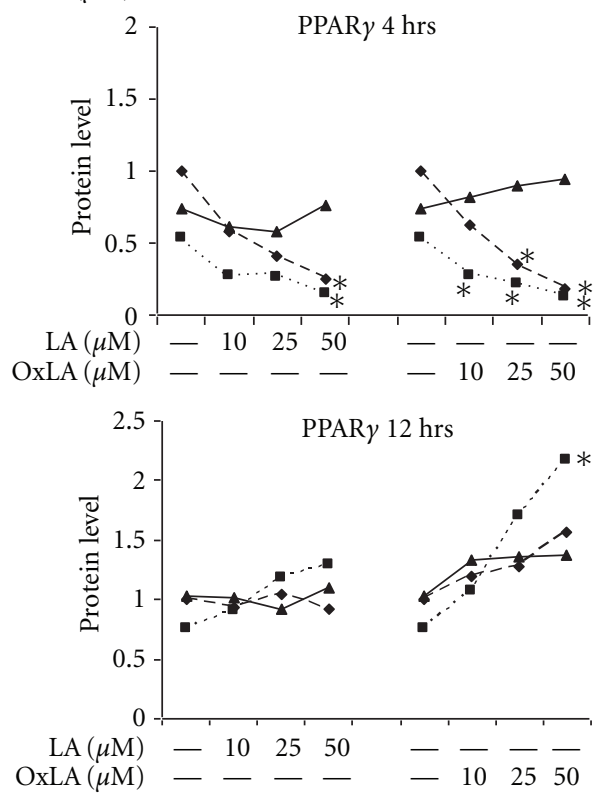

(b)

PPRE

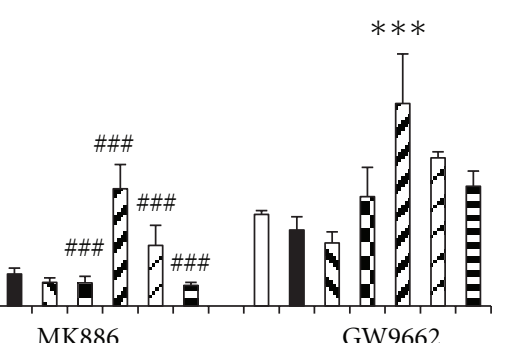

\OxLA $25(\mu \mathrm{M})$

国 OxLA $50(\mu \mathrm{M})$

(c)

FIGURE 1: $\omega$-6 lipids modulate PPAR protein levels and PPRE transactivity in a time-dependent manner. Western blotting of RASMC lysates treated with 10-50 $\mu \mathrm{M}$ of LA and OxLA for 0-12 hrs using PPAR $\alpha$ and PPAR $\gamma$ antibody shows induction of PPAR $\alpha$ at acute phase and PPAR $\gamma$ at subacute phase. Control (CTRL) was defined as the cells treated with vehicle only. The results were expressed as mean \pm SEM (Standard Error of Mean) defined by the ratio of protein levels in treated samples compared to CTRL. All data were normalized to $\beta$-actin (housekeeping protein) (a) PPAR $\alpha$ protein levels after $1 \mathrm{hr}, 4 \mathrm{hr}, 12 \mathrm{hrs}$ treatment. (b) PPAR $\gamma$ protein levels after $1 \mathrm{hr}, 4 \mathrm{hr}, 12 \mathrm{hrs}$ treatment. The figure is a representation of three independent blots. One way ANOVA was used for the comparison between two treatments. Significance was confirmed using post hoc analysis using Fisher LSD test. ${ }^{*} P<0.05$. (c) PPAR transactivity was measured in PPRE-luciferase transfected RASMCs which were pretreated with $10 \mu \mathrm{M}$ MK886 (PPAR $\alpha$ antagonist) or $1 \mu \mathrm{M}$ GW9662 (PPAR $\gamma$ antagonist) followed by exposure to $10-50 \mu \mathrm{M}$ LA or OxLA for $4 \mathrm{hrs}$. The assay were run in duplicates and repeated three independent times. The results were expressed as mean relative luciferase activity \pm SEM (Standard Error of Mean). One way ANOVA was used for the comparison between two treatments. Significance was confirmed using post hoc analysis using Fisher LSD test. * compared to CTRL, $P<0.05$; ${ }^{*}$ compared to $10 \mu \mathrm{M}$ concentration, $P<0.05$. 

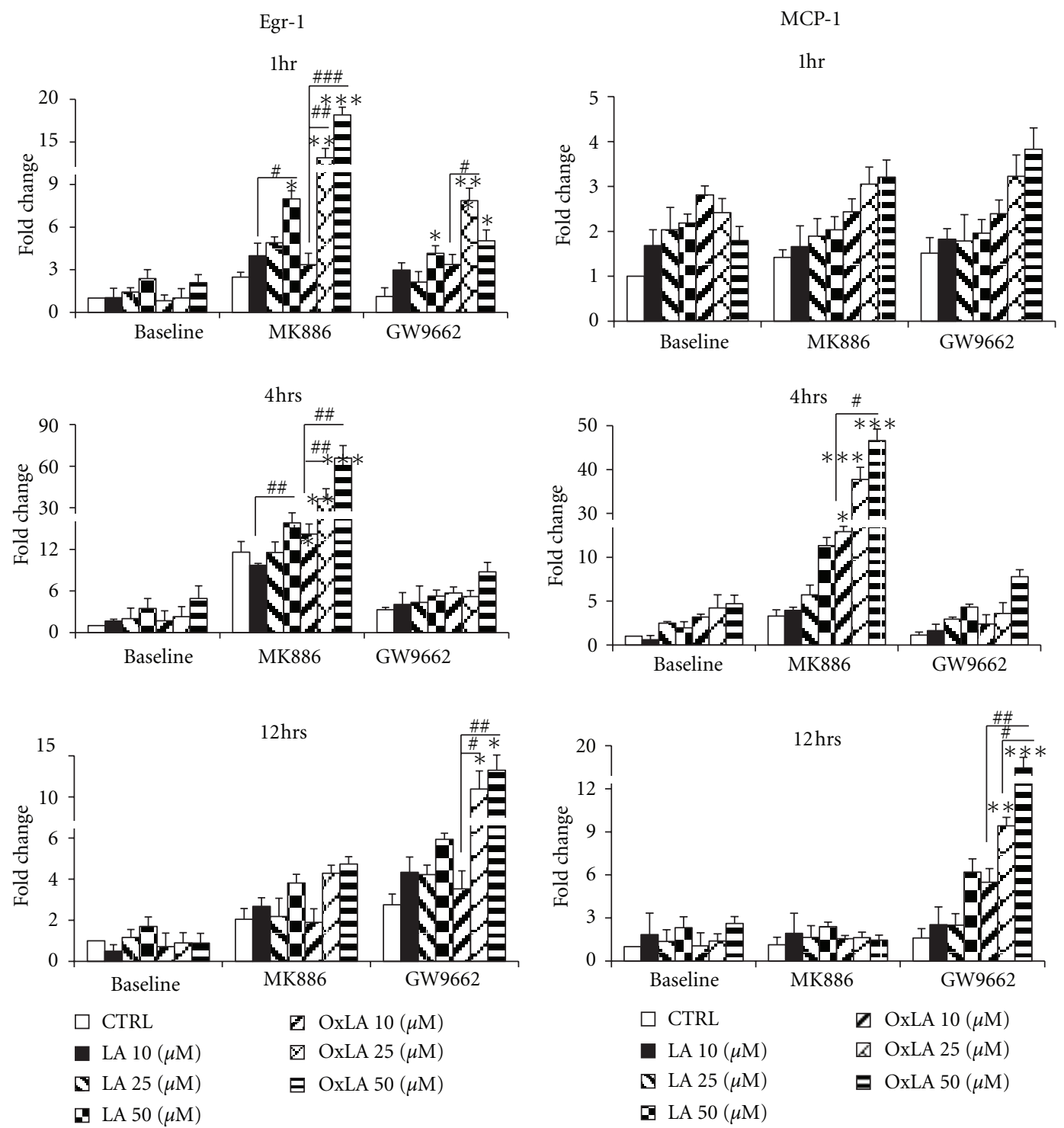

(a)

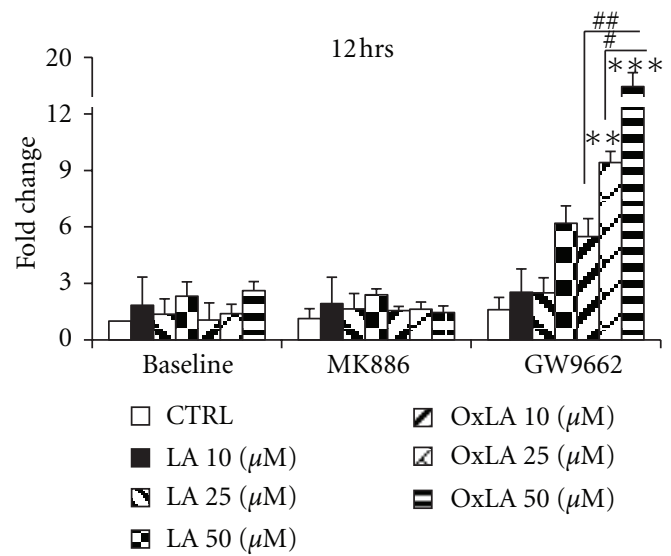

(b)

FIGURE 2: Ligand-mediated regulation of PPAR transactivity altered Egr-1/MCP-1 mRNA levels. Downregulation of PPAR $\alpha$ or $\gamma$ by pretreatment of RASMCs with $10 \mu \mathrm{M}$ MK886 or $1 \mu \mathrm{M}$ GW9662 followed by exposure to $10-50 \mu \mathrm{M}$ LA or OxLA for 1-12 hrs resulted in time-dependent induction of Egr-1 and MCP-1 mRNA levels as analyzed using qRT-PCR. Control-(CTRL-) vehicle only. mRNA levels were expressed as fold change \pm SEM (Standard error of $\triangle$ CT mean). (a) Egr-1 mRNA levels at 1, 4 and 12 hrs; (b) MCP-1 mRNA levels at $1 \mathrm{hr}, 4$ and $12 \mathrm{hrs}$. One way ANOVA was used for comparison between two treatments. Significance was confirmed using Fisher LSD test. * compared to CTRL, ${ }^{*}$ compared to $10 \mu \mathrm{M}$ concentration.

3.2. Ligand-Mediated Regulation of PPAR Transactivity Alters Egr-1/MCP-1 mRNA Levels. $\omega-6$ lipids and its oxidized forms have dual effects on vascular cells. Since these lipids target both PPAR and Egr-1, we speculated that in the absence of PPARs (either by antagonizing the receptor using chemical antagonists or by siRNA approach), the $\omega-6$ lipids will be able to activate Egr-1 and proinflammatory effects. The results shown in Figure 2 indicate that in the presence of a PPAR $\alpha$ antagonist MK886, the $\omega-6$ lipids, LA, and OxLA had an immediate effect (acute phase) on Egr-1 and its downstream target MCP-1 mRNA levels. At 1 hour, both lipids significantly induced Egr-1 mRNA levels (3-20 fold) (Figures 2(a)-2(b)) but only had minimal effect on MCP-1 (1-2-fold), at all concentrations (10-50 $\mu \mathrm{M}$ LA and OxLA) tested, compared to vehicle CTRL. This induction was further increased around $4 \mathrm{hrs}$, when levels of Egr-1 (10-80-fold) and MCP-1 (5-45-fold) by LA and Ox-LA was induced by $3-5$ times higher than after $1 \mathrm{hr}$ treatment and compared to vehicle CTRL. But around 12 hours, the Egr1/MCP-1 levels returned to near baseline levels. Minimal effects on Egr-1/MCP-1 were observed by the antagonists themselves. 


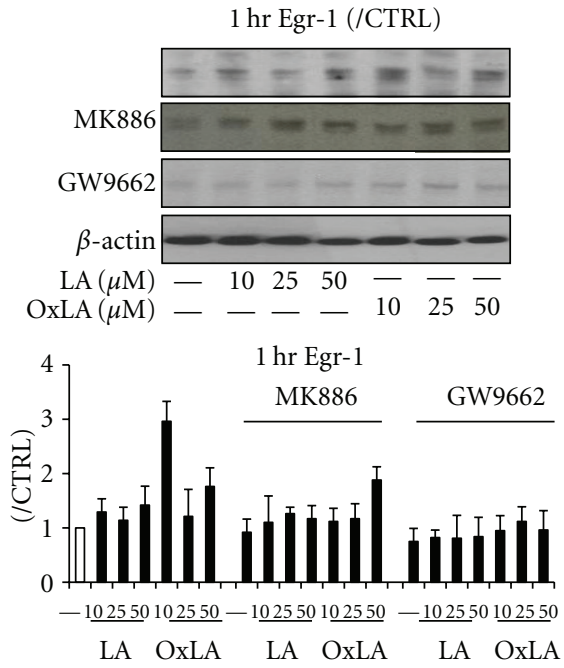

(a)

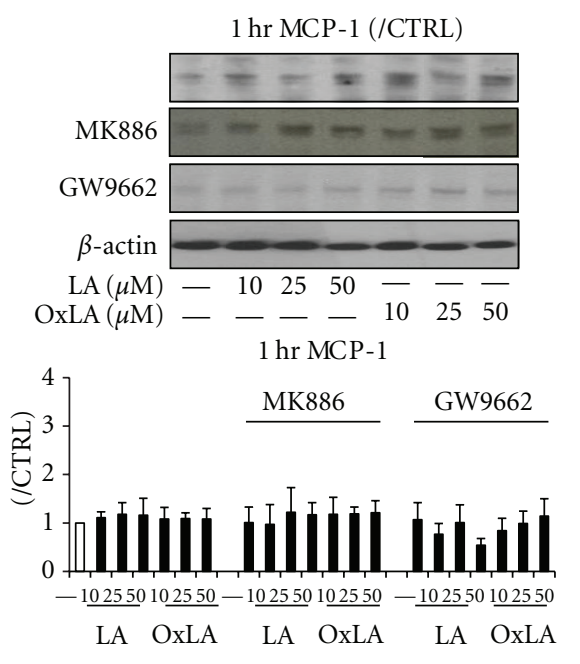

(d)

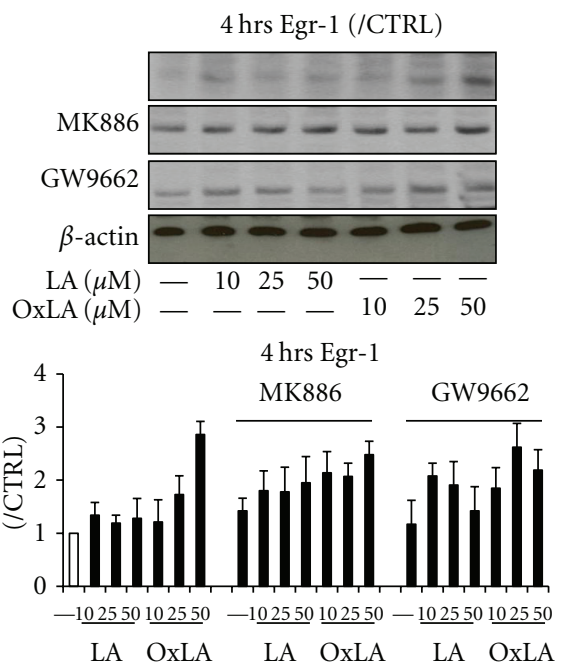

(b)

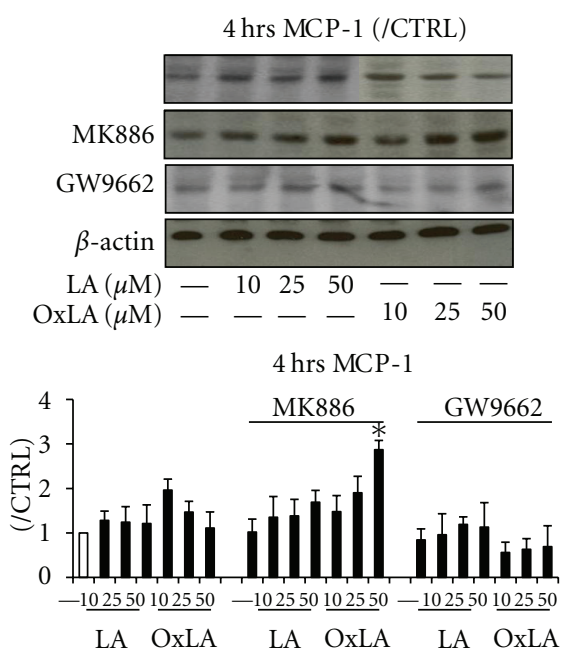

(e)

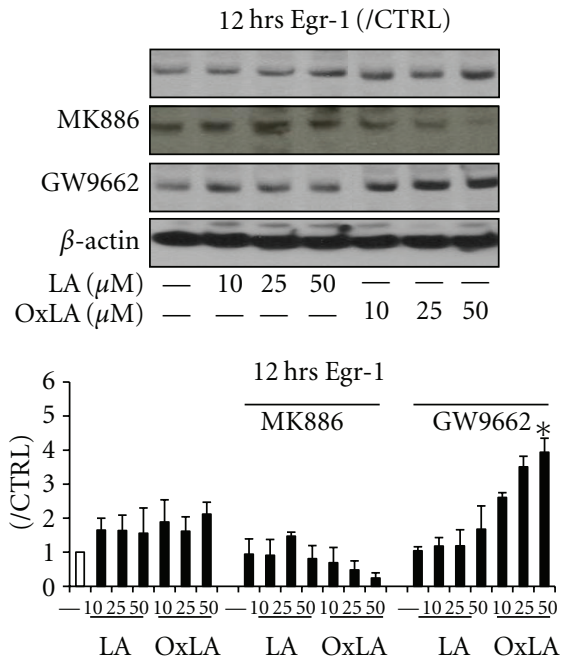

(c)

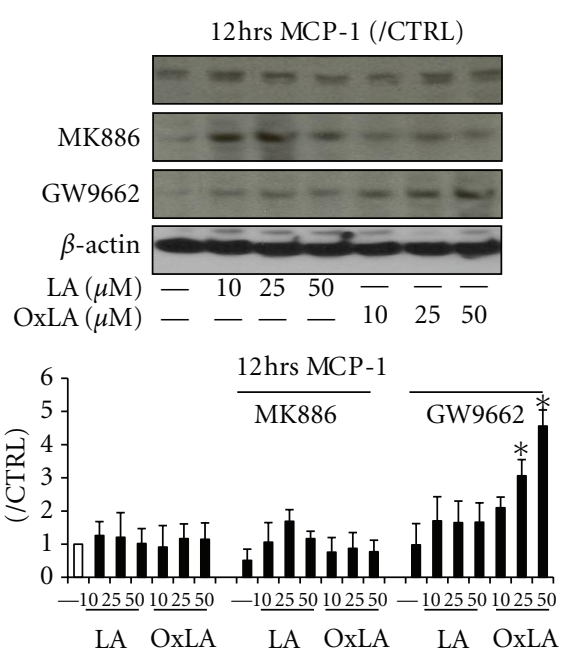

(f)

FIGURE 3: PPAR mediated alteration in Egr-1/MCP-1 protein levels by $\omega-6$ lipids. Egr-1 and MCP-1 protein levels were determined using Western blot in cells exposed to $\omega$-6 lipids after pretreatment with PPAR $\alpha$ or $\gamma$ antagonists, MK886 or GW9662. Control-(CTRL) vehicle only. The results were expressed as mean \pm SEM (Standard Error of Mean). (a-c) Egr-1 protein levels after 1, 4, and 12 hrs; (d-f) MCP-1 protein levels after 1, 4, and $12 \mathrm{hrs}$. One way ANOVA was used for the comparison between two treatments. Significance was confirmed using post hoc Fisher LSD test. ${ }^{*} P<0.05$.

In contrast, in the presence of PPAR $\gamma$ antagonist GW9662, the $\omega-6$ lipids had a higher induction of Egr-1 and MCP-1 at a later time point, that is, 12 hours (subacute phase) (Figures 2(a)-2(b)). There was a minimal or no apparent induction of Egr-1 or MCP-1 at $1-4 \mathrm{hrs}$ at all concentrations of LA and OxLA tested compared to vehicle CTRL. However, after 12 hours, cells exposed to GW9662 exhibited enhanced induction of Egr-1 and MCP-1 (5-10fold) mRNA levels especially at higher concentrations of OxLA [18 fold, $50 \mu \mathrm{M}$ ] compared to vehicle CTRL.

3.3. PPAR-Mediated Alteration in Egr-1/MCP-1 Protein Levels by $\omega-6$ Lipids. Western blotting of the cell lysates obtained from the above treated cells indicated that both LA and OxLA had similar trends on Egr-1 or MCP-1 protein levels as seen with the mRNA levels. As shown in Figures 3(a)-3(b), at $1 \mathrm{hr}$ and 4 hrs (acute phase), LA and OxLA had minimal induction of Egr-1 protein. However, pretreatment with MK886 (PPAR $\alpha$ antagonist) exhibited a slightly larger induction of Egr-1 (2-fold). At $12 \mathrm{hrs}$ the baseline Egr-1 protein levels were higher than that seen in the acute phase, however, when cells were pretreated with MK886 followed by exposure to $\omega$ 6 lipids there was a downregulation of Egr-1 protein levels, whereas pretreatment with GW9662, exhibited higher levels of Egr-1 protein, in a concentration-dependent manner (Figure 3(c)) compared to vehicle CTRL. This induction reached significance at $50 \mu \mathrm{M}$ OxLA $(P<0.05)$. 
Similar trends were observed with the Egr-1 downstream target, MCP-1 protein levels in the presence of $\omega-6$ lipids (Figures 3(d)-3(f)). MK886 pretreatment had an initial increase in MCP-1 levels at $4 \mathrm{hrs}$ followed by a return to baseline levels at $12 \mathrm{hrs}$, upon exposure to $\omega$ - 6 lipids. On the other hand, these lipids had minimal effects on MCP-1 protein levels when PPAR $y$ was inhibited (GW9662 pretreated cells) at all time points tested except for the higher doses of the OxLA at $12 \mathrm{hrs}$.

3.4. siRNA-Mediated Downregulation of PPARs Modulated Egr-1 Levels. The results above indicated that inhibition of PPARs by antagonists modulated Egr- 1 levels by $\omega-6$ lipids. In order to validate the above findings where PPARs were downregulated by the use of antagonists and establish the relationship between PPAR levels and Egr-1 modulation by $\omega-6$ lipids, in this experiment we used siRNA approach to downregulate either PPAR $\alpha$ or PPAR $\gamma$ in RASMCs followed by treatment with different concentrations of $\omega-6$ lipids for 4 or 12 hrs. As shown in Figure 4, our preliminary findings indicated that compared to the concentration-dependent Egr-1 induction by $\omega-6$ lipids the nontargeting siRNA group, the Egr- 1 levels were upregulated by over $20-25$-fold when PPAR $\alpha$ was downregulated by siRNA approach at $4 \mathrm{hrs}$ compared to PPAR $y$ downregulation. The effects of $\omega-6$ lipids were less apparent at the subacute phase. These initial findings have similar trends in Egr-1 levels as observed in the presence of PPAR antagonists.

3.5. Alterations in Egr-1/MCP-1 Levels by w-6 Lipids Modulates Monocyte Adhesion to RASMCs. Monocyte/macrophage infiltration into the subendothelial space of arteries is an important step in the atherogenic process [48]. Egr1/MCP-1 interplay plays an important role in promoting atherogenic lipids (OxLDLs) initiating monocyte infiltration and adhesion during atherosclerosis [49-51]. Since, our results thus far indicated that $\omega-6$ lipids by regulating PPAR transactivity were able to modulate Egr-1/MCP-1 mRNA and protein levels, we speculated that this will alter monocyte adhesion to vascular cells in a time-dependent fashion. Figures 5(a)-5(b) demonstrate that in the absence of PPAR antagonists, $\omega-6$ lipids had a concentration-dependent increase in the number of monocytes adhered to RASMCs $(P<0.05)$ at both 4 and $12 \mathrm{hrs}$ treatments. However, in the presence of PPAR antagonists, these lipid ligands had a PPAR-subtype-dependent modulation of monocyte adhesion to RASMCs. Pretreatment with MK886 (PPAR $\alpha$ antagonist) significantly increased monocyte adhesion by PPAR lipid ligands at 4 hours, whereas PPAR $y$ inhibition (GW9662 treated) increased adhesion at a later time point (12 hours) reflecting the increase in Egr-1/MCP-1 mRNA and protein levels in the presence of these antagonists at these respective time points. PPAR antagonists by themselves did seem to have an effect on the monocyte adhesion to RASMCs, but the lipid treatments were in addition to what was observed at baseline.

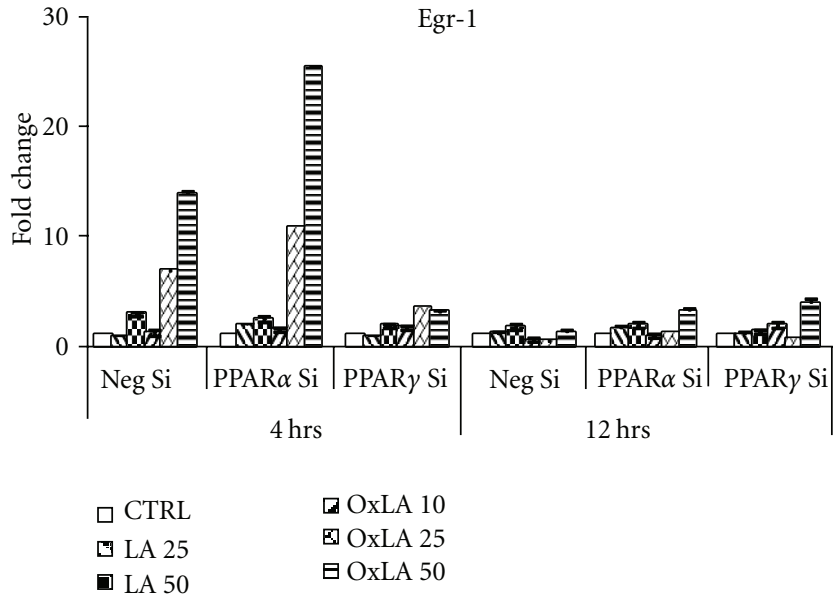

FIgure 4: Downregulation of PPARs by siRNA alters $\omega$-6 lipidmediated induction of Egr-1 mRNA: RASMCs were transfected with SMART-pool siRNA duplexes of PPAR $\alpha$, PPAR $\gamma$ or nontargeting control siRNA, followed by treatment with $\omega-6$ lipids for 4 and 12 hrs. Preliminary findings indicated Egr-1 mRNA levels were upregulated when $\operatorname{PPAR} \alpha$ was knocked down compared to PPAR $y$ knockdown as determined by qRT-PCR. The fold change was calculated by comparing lipid treatments with vehicle controls in each siRNA group. All values were normalized to $\beta$-actin (housekeeping gene). mRNA levels were expressed as fold change \pm SEM (Standard error of $\triangle \mathrm{CT}$ mean).

\section{Discussion}

Our study for the first time demonstrates that atherogenic $\omega-6$ lipids, such as linoleic acid and its oxidized forms (13-HPODE/13HODE), (abundant in diet and associated with OxLDL) modulate PPAR/Egr-1 crosstalk, resulting in altered vSMC function. In the presence of PPAR antagonists, $\omega-6$ lipids altered Egr-1-mediated responses through its divergent effect on PPAR subtypes in a time-dependent manner. Though our studies used these lipids in the free form, in physiology these fatty acids are either part of membrane lipids or major components of lipoproteins. We predict that oxidation of most of the dietary lipids both in the free form or in an esterified form will have similar effects. Depending on its dose and time of exposure, $\omega-6$ lipids have biphasic effects on vascular inflammation [5153]. vSMCs that make up the intimal and medial layer of the vessel wall play an important role in the initiation and early progression of atherosclerosis [54]. $\omega-6$ lipids mediate smooth muscle migration, proliferation, and apoptosis during the atherosclerotic process [55]. These lipids have multiple proinflammatory effects on the vasculature which include, activation of adhesion molecules, chemoattractants, $\mathrm{NF} \kappa \mathrm{B}$ pathway, and activation of scavenger receptors leading to foam cell formation $[50,56,57]$. On the other hand, we and others have also shown anti-inflammatory effects of $\omega-6$ lipids, such as their ability to inhibit tumor necrosis alpha $(\mathrm{TNF} \alpha)$ production, inhibition of nitric oxide production, and activation of antioxidant enzymes [53, 58-60].

The zinc finger transcription factor, Egr-1, is expressed in all vascular cells including endothelial cells, smooth muscle 

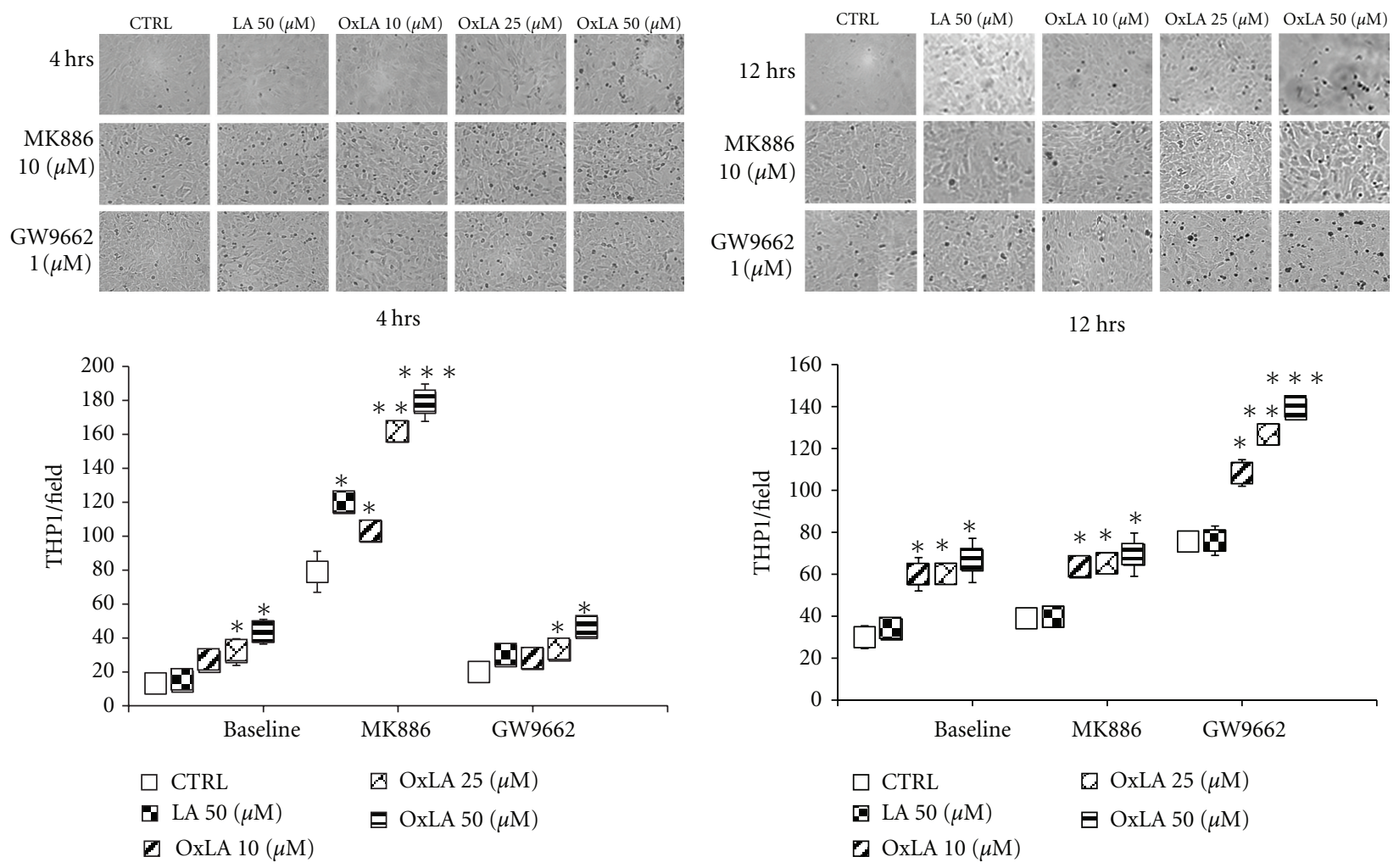

(a)

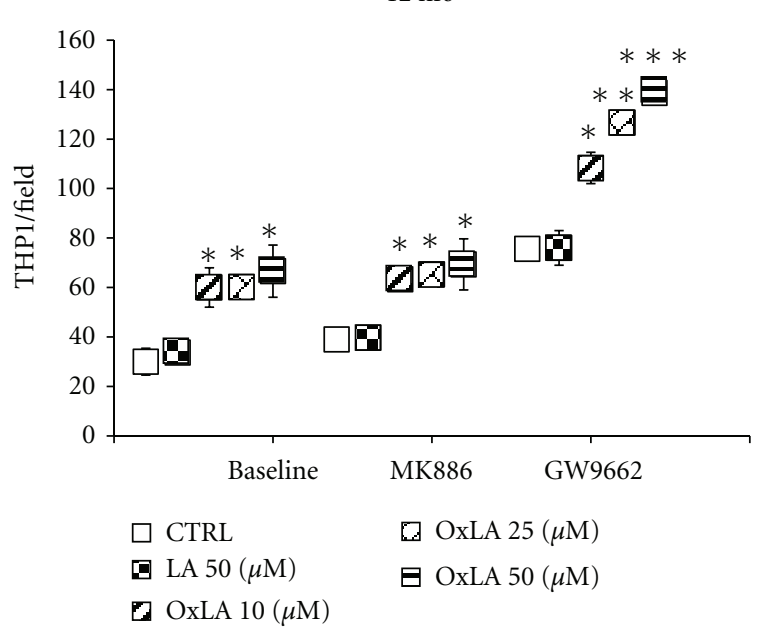

(b)

FIGURE 5: Alterations in Egr-1/MCP-1 by $\omega$-6 lipids resulted in altered monocyte (THP1) adhesion to RASMCs THP1 (human monocyte) cells adhesion to RASMCs exposed to LA and OxLA (with or without pretreatment to MK886 and GW9662) was determined by counting the number of cells in a $3 \times 3$ field on an inverted fluorescent microscope. Results showed that monocyte adhesion reflected the alterations in Egr-1 and MCP-1 levels by $\omega-6$ lipids by an increase in adherent monocyte cell number at 4 hrs when PPAR $\alpha$ was downregulated and increase in adherent cell number at $12 \mathrm{hrs}$ when PPAR $\gamma$ was downregulated. The data presented represents mean numbers of THP1 cells adhered to RASMCs in each field \pm SEM (Standard Error of Mean). (a) monocyte adhesion at 4 hrs; (b) monocyte adhesion at 12 hrs. ${ }^{*} P<0.05$, ${ }^{* *} P<0.01,{ }^{* * *} P<0.005$.

cells, and monocyte/macrophages [61]. Egr-1 is also upregulated in the atherosclerotic fibrous cap [62]. Oxidative stress, an important player in atherosclerosis can induce Egr-1 $[63,64]$ and conversely, deletion of Egr-1 showed a protective effect in the Apo $\mathrm{E}^{-/-}$atherosclerosis mouse model [65, 66]. Several factors including platelet-derived growth factor $[67,68]$, fibroblast growth factor [69], angiotensin-II [70], and oxidative stress [71] activates Egr-1 in vascular tissues including vascular smooth muscle cells [70]. A recent study demonstrated that oxidants such as $\mathrm{H}_{2} \mathrm{O}_{2}$, activated Egr-1 in vascular smooth muscle cells in both a time- and dosedependent manner [64]. In the present study, in the presence of PPAR antagonists, the $\omega-6$ lipids had a biphasic effect on PPAR subtypes, an activation of PPAR $\alpha$ in the acute phase (1-4 hours), and PPAR $y$ in the subacute phase (12 hours). The mechanism behind this biphasic effect can only presently be speculated to be a probable regulation of PPAR turnover by these lipids. $\omega-6$ lipids are physiological ligands of PPARs and biophysical studies confirmed a covalent interaction between these lipids with PPARs $[29,30]$. These interactions were different from that seen with known PPAR synthetic ligands that is, rosiglitazone or fibrates. In the present study, both from the preliminary PPAR siRNA findings and the PPRE-luciferase transactivity studies in RASMCs, in the presence of PPAR antagonists indicated that $\omega-6$ lipids had a higher induction of PPAR $\alpha$ promoter compared to PPAR $\gamma$, however, we still observed that blocking PPAR $\gamma$ did enhance Egr-1/MCP-1 in the subacute phase. This can probably be attributed to increased generation of intracellular oxidative stress including $\mathrm{H}_{2} \mathrm{O}_{2}[58,72]$ at the subacute phase or through the inhibition of Egr-1 by PPAR $\gamma$ [20, 23].

In both atherosclerotic and ischemic models, PPAR ligands are known to inhibit multiple proinflammatory genes by inhibiting Egr-1 $[20,21,73]$. Our findings further showed that the time-dependent effect of OxLA on PPARs/Egr-1 crosstalk and the resultant alterations in Egr-1/MCP-1 levels also resulted in altered smooth muscle cell chemoattraction to monocytes. Selective blocking of PPAR $\alpha$ (MK886) enhanced monocyte adhesion at $4 \mathrm{hrs}$, whereas blocking of PPAR $y$ (GW9662) enhanced monocyte adhesion at $12 \mathrm{hrs}$. This data further supports the time-dependent paradoxical effects of OxLA during the atherogenesis process $[50,53$, 59]. Since, pretreatment with MK886 exhibited a higher inhibition of OxLA-induced PPRE transactivity but a higher 
induction of Egr-1/MCP-1 and monocyte adhesion than GW9662, it can be speculated that the $\omega-6$ lipids seems to have a predominant influence on $\operatorname{PPAR} \alpha$ compared to PPAR $\gamma$ in vSMCs.

In the present studies, though both unoxidized and oxidized linoleic acid exhibited similar regulatory effects on Egr-1/MCP-1 and PPAR levels, at similar concentrations, OxLA had a more dramatic effect than LA. Both unoxidized and oxidized forms are ligands of PPARs and have been shown to have similar vascular effects. This may be explained by (i) the ability of LA similar to OxLA to generate reactive oxygen species (ROS), though at lower levels, by mitochondrial oxidation [74] and fatty acid peroxisomal degradation [75]. ROS generated through these pathways induces transcription factors including $\mathrm{NF} \kappa \mathrm{B}$ and Egr-1 $[71,76,77]$. (ii) Secondly, other than dietary and other extracellular sources, the hydrolysis of esterified lipids by intracellular lipoxygenase and cycloxygenase pathway can also generate oxidized lipids [78, 79] from LA.

Our results, to our knowledge, for the first time demonstrate that $\omega-6$ lipids depending on the dose and time of exposure on vascular cells have a preferential activation of specific PPAR subtypes. Whether this preferential activation of PPAR subtypes is reflective of the ability of these lipids to modulate PPAR turnover is currently being investigated. The interactions of these lipid ligands on both Egr-1 and PPAR subtypes results in an altered crosstalk between Egr-1 and PPARs which ultimately reflected in altered atherogenic response by the vascular cells (Scheme 1). Our results provide novel insights into the regulatory role of dietary $\omega$ 6 lipids on two of the major transcription factors that are relevant to atherosclerosis, PPAR, and Egr-1 with differing vascular effects.

\section{Acknowledgments}

The authors acknowledge the grant support from $\mathrm{NIH}$, HL074239 (NS), and 5P20RR016477 (NS), MG-WV-NASA fellowship.

\section{References}

[1] L. M. Khachigian, "Early growth response-1 in cardiovascular pathobiology," Circulation Research, vol. 98, no. 2, pp. 186191, 2006.

[2] U. R. Pendurthi, J. T. Williams, and L. V. M. Rao, "Inhibition of tissue factor gene activation in cultured endothelial cells by curcumin: suppression of activation of transcription factors Egr-1, AP-1, and NF- $\kappa$ B," Arteriosclerosis, Thrombosis, and Vascular Biology, vol. 17, no. 12, pp. 3406-3413, 1997.

[3] J. Yao, N. Mackman, T. S. Edgington, and S. T. Fan, "Lipopolysaccharide induction of the tumor necrosis factor$\alpha$ promoter in human monocytic cells: regulation by Egr-1, c-Jun, and NF- $\kappa$ B transcription factors," Journal of Biological Chemistry, vol. 272, no. 28, pp. 17795-17801, 1997.

[4] X. Bao, C. Lu, and J. A. Frangos, "Temporal gradient in shear but not steady shear stress induces PDGF-A and MCP-1 expression in endothelial cells: role of $\mathrm{NO}, \mathrm{NF} \kappa \mathrm{B}$, and egr-1," Arteriosclerosis, Thrombosis, and Vascular Biology, vol. 19, no. 4, pp. 996-1003, 1999.
[5] R. K. Giri, S. K. Selvaraj, and V. K. Kalra, "Amyloid peptideinduced cytokine and chemokine expression in THP-1 monocytes is blocked by small inhibitory RNA duplexes for early growth response-1 messenger RNA," Journal of Immunology, vol. 170, no. 10, pp. 5281-5294, 2003.

[6] T. Maekawa, N. Takahashi, T. Honda et al., "Porphyromonas gingivalis antigens and interleukin- 6 stimulate the production of monocyte chemoattractant protein-1 via the upregulation of early growth response- 1 transcription in human coronary artery endothelial cells," Journal of Vascular Research, vol. 47, no. 4, pp. 346-354, 2009.

[7] S. Goetze, U. Kintscher, K. Kaneshiro et al., "TNF $\alpha$ induces expression of transcription factors c-fos, Egr-1, and Ets-1 in vascular lesions through extracellular signal-regulated kinases 1/2," Atherosclerosis, vol. 159, no. 1, pp. 93-101, 2001.

[8] S. Z. Duan, M. G. Usher, and R. M. Mortensen, "PPARs: the vasculature, inflammation and hypertension," Current Opinion in Nephrology and Hypertension, vol. 18, no. 2, pp. 128-133, 2009.

[9] E. Robinson and D. J. Grieve, "Significance of peroxisome proliferator-activated receptors in the cardiovascular system in health and disease," Pharmacology and Therapeutics, vol. 122, no. 3, pp. 246-263, 2009.

[10] N. Marx, H. Duez, J. C. Fruchart, and B. Staels, "Peroxisome proliferator-activated receptors and atherogenesis: regulators of gene expression in vascular cells," Circulation Research, vol. 94, no. 9, pp. 1168-1178, 2004.

[11] R. E. Law, S. Goetze, X. P. Xi et al., "Expression and function of PPAR $\gamma$ in rat and human vascular smooth muscle cells," Circulation, vol. 101, no. 11, pp. 1311-1318, 2000.

[12] S. T. de Dios, R. C. O’Brien, and P. J. Little, "Clinical thiazolidinediones as PPAR $y$ ligands with the potential for the prevention of cardiovascular disease in diabetes," Current Diabetes Reviews, vol. 2, no. 2, pp. 227-239, 2006.

[13] Z. Israelian-Konaraki and P. D. Reaven, "Peroxisome proliferator-activated receptor-alpha and atherosclerosis: from basic mechanisms to clinical implications," Cardiology in Review, vol. 13, no. 5, pp. 240-246, 2005.

[14] J. C. Fruchart, "Peroxisome proliferator-activated receptoralpha $(\operatorname{PPAR} \alpha)$ : at the crossroads of obesity, diabetes and cardiovascular disease," Atherosclerosis, vol. 205, no. 1, pp. 1-8, 2009.

[15] R. Altman, D. D. Motton, R. S. Kota, and J. C. Rutledge, "Inhibition of vascular inflammation by dehydroepiandrosterone sulfate in human aortic endothelial cells: roles of PPAR $\alpha$ and NF- $\kappa$ B," Vascular Pharmacology, vol. 48, no. 2-3, pp. 76-84, 2008.

[16] V. R. Babaev, H. Ishiguro, L. Ding et al., "Macrophage expression of peroxisome proliferator-activated receptor- $\alpha$ reduces atherosclerosis in low-density lipoprotein receptor-deficient mice," Circulation, vol. 116, no. 12, pp. 1404-1412, 2007.

[17] G. Krönke, A. Kadl, E. Ikonomu et al., "Expression of heme oxygenase-1 in human vascular cells is regulated by peroxisome proliferator-activated receptors," Arteriosclerosis, Thrombosis, and Vascular Biology, vol. 27, no. 6, pp. 1276-1282, 2007.

[18] J. Barlic and P. M. Murphy, "An oxidized lipid-peroxisome proliferator-activated receptor $\gamma$-chemokine pathway in the regulation of macrophage-vascular smooth muscle cell adhesion," Trends in Cardiovascular Medicine, vol. 17, no. 8, pp. 269-274, 2007.

[19] Y. Jung, S. Song, and C. Choi, "Peroxisome proliferator activated receptor $\gamma$ agonists suppress TNF $\alpha$-induced ICAM-1 
expression by endothelial cells in a manner potentially dependent on inhibition of reactive oxygen species," Immunology Letters, vol. 117, no. 1, pp. 63-69, 2008.

[20] M. Okada, S. F. Yan, and D. J. Pinsky, "Peroxisome proliferator-activated receptor- $\gamma$ (PPAR- $\gamma$ ) activation suppresses ischemic induction of Egr-1 and its inflammatory gene targets," FASEB Journal, vol. 16, no. 14, pp. 1861-1868, 2002.

[21] S. Ichihara, K. Obata, Y. Yamada et al., "Attenuation of cardiac dysfunction by a PPAR- $\alpha$ agonist is associated with downregulation of redox-regulated transcription factors," Journal of Molecular and Cellular Cardiology, vol. 41, no. 2, pp. 318-329, 2006.

[22] M. Fu, J. Zhang, Y. Lin, X. Zhu, M. U. Ehrengruber, and Y. E. Chen, "Early growth response factor-1 is a critical transcriptional mediator of peroxisome proliferator-activated receptor- $\gamma 1$ gene expression in human aortic smooth muscle cells," Journal of Biological Chemistry, vol. 277, no. 30, pp. 26808-26814, 2002.

[23] M. Fu, J. Zhang, Y. Lin et al., "Early stimulation and late inhibition of peroxisome proliferator-activated receptor $\gamma$ $(\operatorname{PPAR} \gamma)$ gene expression by transformino growth factor $\beta$ in human aortic smooth muscle cells: role of early growthresponse factor-1 (Egr-1), activator protein 1 (AP1) and Smads," Biochemical Journal, vol. 370, no. 3, pp. 1019-1025, 2003.

[24] P. Delerive, C. Furman, E. Teissier, J. C. Fruchart, P. Duriez, and B. Staels, "Oxidized phospholipids activate PPAR $\alpha$ in a phospholipase A2-dependent manner," FEBS Letters, vol. 471, no. 1, pp. 34-38, 2000.

[25] L. Nagy, P. Tontonoz, J. G. A. Alvarez, H. Chen, and R. M. Evans, "Oxidized LDL regulates macrophage gene expression through ligand activation of PPAR $\gamma$," Cell, vol. 93, no. 2, pp. 229-240, 1998.

[26] S. A. Kliewer, J. M. Lenhard, T. M. Willson, I. Patel, D. C. Morris, and J. M. Lehmann, "A prostaglandin J2 metabolite binds peroxisome proliferator-activated receptor $\gamma$ and promotes adipocyte differentiation," Cell, vol. 83 , no. 5, pp. 813819, 1995.

[27] B. M. Forman, P. Tontonoz, J. Chen, R. P. Brun, B. M. Spiegelman, and R. M. Evans, "15-deoxy- $\Delta 12$, 14-prostaglandin J2 is a ligand for the adipocyte determination factor PPAR $\gamma$," Cell, vol. 83, no. 5, pp. 803-812, 1995.

[28] J. T. Huang, J. S. Welch, M. Ricote et al., "Interleukin-4dependent production of PPAR- $\gamma$ ligands in macrophages by 12/15-lipoxygenase," Nature, vol. 400, no. 6742, pp. 378-382, 1999.

[29] T. Itoh, L. Fairall, K. Amin et al., "Structural basis for the activation of PPAR $\gamma$ by oxidized fatty acids," Nature Structural and Molecular Biology, vol. 15, no. 9, pp. 924-931, 2008.

[30] K. W. Nettles, "Insights into PPAR $\gamma$ from structures with endogenous and covalently bound ligands," Nature Structural and Molecular Biology, vol. 15, no. 9, pp. 893-895, 2008.

[31] J. Whelan, "The health implications of changing linoleic acid intakes," Prostaglandins Leukotrienes and Essential Fatty Acids, vol. 79, no. 3-5, pp. 165-167, 2008.

[32] P. M. Kris-Etherton, K. D. Hecker, and A. E. Binkoski, "Polyunsaturated fatty acids and cardiovascular health," Nutrition Reviews, vol. 62, no. 11, pp. 414-426, 2004.

[33] E. M. Berry, "Who's afraid of n-6 polyunsaturated fatty acids? Methodological considerations for assessing whether they are harmful," Nutrition, Metabolism and Cardiovascular Diseases, vol. 11, no. 3, pp. 181-188, 2001.
[34] I. Staprans, J. H. Rapp, X. M. Pan, D. A. Hardman, and K. R. Feingold, "Oxidized lipids in the diet accelerate the development of fatty streaks in cholesterol-fed rabbits," Arteriosclerosis, Thrombosis, and Vascular Biology, vol. 16, no. 4, pp. 533-538, 1996.

[35] N. Totani, M. Burenjargal, M. Yawata, and Y. Ojiri, "Chemical properties and cytotoxicity of thermally oxidized oil," Journal of Oleo Science, vol. 57, no. 3, pp. 153-160, 2008.

[36] J. C. Alexander, "Chemical and biological properties related to toxicity of heated fats," Journal of Toxicology and Environmental Health, vol. 7, no. 1, pp. 125-138, 1981.

[37] W. C. Byrdwell and W. E. Neff, "Autoxidation products of normal and genetically modified canola oil varieties determined using liquid chromatography with mass spectrometric detection," Journal of Chromatography A, vol. 905, no. 1-2, pp. 85-102, 2001.

[38] S. Wassmann, K. Wassmann, and G. Nickenig, "Modulation of oxidant and antioxidant enzyme expression and function in vascular cells," Hypertension, vol. 44, no. 4, pp. 381-386, 2004.

[39] S. Wassmann, K. Wassmann, and G. Nickenig, "Regulation of antioxidant and oxidant enzymes in vascular cells and implications for vascular disease," Current Hypertension Reports, vol. 8, no. 1, pp. 69-78, 2006.

[40] S. Parthasarathy, N. K. Merchant, M. Penumetcha, and N. Santanam, "Oxidation and cardiovascular disease-potential role of oxidants in inducing antioxidant defense enzymes," Journal of Nuclear Cardiology, vol. 8, no. 3, pp. 379-389, 2001.

[41] J. Fruebis, S. Parthasarathy, and D. Steinberg, "Evidence for a concerted reaction between lipid hydroperoxides and polypeptides," Proceedings of the National Academy of Sciences of the United States of America, vol. 89, no. 22, pp. 1058810592, 1992.

[42] M. W. Pfaffl, "A new mathematical model for relative quantification in real-time RT-PCR," Nucleic Acids Research, vol. 29, no. 9, p. E45, 2001.

[43] O. H. Lowry, N. J. Rosebrough, A. L. Farr, and R. J. Randall, "Protein measurement with the Folin phenol reagent," The Journal of Biological Chemistry, vol. 193, no. 1, pp. 265-275, 1951.

[44] K. Jaworski, F. Kinard, D. Goldstein et al., "S-nitrosothiols do not induce oxidative stress, contrary to other nitric oxide donors, in cultures of vascular endothelial or smooth muscle cells," European Journal of Pharmacology, vol. 425, no. 1, pp. 11-19, 2001.

[45] J. S. Yuan, A. Reed, F. Chen, and C. N. Stewart, "Statistical analysis of real-time PCR data," BMC Bioinformatics, vol. 7, article no. 85, 2006.

[46] M. H. Hsu, U. Savas, K. J. Griffin, and E. F. Johnson, "Identification of peroxisome proliferator-responsive human genes by elevated expression of the peroxisome proliferatoractivated receptor $\alpha$ in HepG2 cells," Journal of Biological Chemistry, vol. 276, no. 30, pp. 27950-27958, 2001.

[47] M. Heinaniemi, J. O. Uski, T. Degenhardt, and C. Carlberg, "Meta-analysis of primary target genes of peroxisome proliferator-activated receptors," Genome Biology, vol. 8, no. 7, article R147, 2007.

[48] Y. I. Miller, S. H. Choi, L. Fang, and S. Tsimikas, "Lipoprotein modification and macrophage uptake: role of pathologic cholesterol transport in atherogenesis," Sub-Cellular Biochemistry, vol. 51, pp. 229-251, 2010.

[49] A. Furnkranz, A. Schober, V. N. Bochkov et al., "Oxidized phospholipids trigger atherogenic inflammation in murine arteries," Arteriosclerosis, Thrombosis, and Vascular Biology, vol. 25, no. 3, pp. 633-638, 2005. 
[50] J. Barlic, Y. Zhang, and P. M. Murphy, "Atherogenic lipids induce adhesion of human coronary artery smooth muscle cells to macrophages by up-regulating chemokine CX3CL1 on smooth muscle cells in a TNF $\alpha$-NF $\kappa \mathrm{B}$-dependent manner," Journal of Biological Chemistry, vol. 282, no. 26, pp. 1916719176, 2007.

[51] K. G. Birukov, "Oxidized lipids: the two faces of vascular inflammation," Current Atherosclerosis Reports, vol. 8, no. 3, pp. 223-231, 2006.

[52] S. Parthasarathy, N. Santanam, S. Ramachandran, and O. Meilhac, "Invited review: potential role of oxidized lipids and lipoproteins in antioxidant defense," Free Radical Research, vol. 33, no. 3, pp. 197-215, 2000.

[53] E. Niki, "Lipid peroxidation: physiological levels and dual biological effects," Free Radical Biology and Medicine, vol. 47, no. 5, pp. 469-484, 2009.

[54] A. C. Doran, N. Meller, and C. A. McNamara, "Role of smooth muscle cells in the initiation and early progression of atherosclerosis," Arteriosclerosis, Thrombosis, and Vascular Biology, vol. 28, no. 5, pp. 812-819, 2008.

[55] M. E. Rosenfeld, "Inflammation, lipids, and free radicals: lessons learned from the atherogenic process," Seminars in Reproductive Endocrinology, vol. 16, no. 4, pp. 249-261, 1998.

[56] B. Friedrichs, M. Toborek, B. Hennig, L. Heinevetter, C. Müller, and R. Brigelius-Flohé, "13-HPODE and 13-HODE modulate cytokine-induced expression of endothelial cell adhesion molecules differently," BioFactors, vol. 9, no. 1, pp. 61-72, 1999.

[57] S. Parthasarathy, N. Santanam, S. Ramachandran, and O. Meilhac, "Potential role of oxidized lipids and lipoproteins in antioxidant defense," Free Radical Research, vol. 33, no. 3, pp. 197-215, 2000.

[58] O. Meilhac, M. Zhou, N. Santanara, and S. Parthasarathy, "Lipid peroxides induce expression of catalase in cultured vascular cells," Journal of Lipid Research, vol. 41, no. 8, pp. 1205-1213, 2000.

[59] C. Marantos, V. Mukaro, J. Ferrante, C. Hii, and A. Ferrante, "Inhibition of the lipopolysaccharide-induced stimulation of the members of the MAPK family in human monocytes/macrophages by 4-hydroxynonenal, a product of oxidized omega-6 fatty acids," American Journal of Pathology, vol. 173, no. 4, pp. 1057-1066, 2008.

[60] A. Huang, C. Li, R. L. Kao, and W. L. Stone, "Lipid hydroperoxides inhibit nitric oxide production in RAW264.7 macrophages," Free Radical Biology and Medicine, vol. 26, no. 5-6, pp. 526-537, 1999.

[61] J. D. Kakisis, C. D. Liapis, and B. E. Sumpio, "Effects of cyclic strain on vascular cells," Endothelium: Journal of Endothelial Cell Research, vol. 11, no. 1, pp. 17-28, 2004.

[62] T. A. McCaffrey, C. Fu, B. Du et al., "High-level expression of Egr-1 and Egr-1-inducible genes in mouse and human atherosclerosis," Journal of Clinical Investigation, vol. 105, no. 5, pp. 653-662, 2000.

[63] R. N. Hasan and A. I. Schafer, "Hemin upregulates Egr-1 expression in vascular smooth muscle cells via reactive oxygen species ERK-1/2-Elk-1 and NF- $\kappa \mathrm{B}$," Circulation Research, vol. 102, no. 1, pp. 42-50, 2008.

[64] C. C. L. Wang, G. Sharma, and B. Draznin, "Early growth response gene-1 expression in vascular smooth muscle cells: effects of insulin and oxidant stress," American Journal of Hypertension, vol. 19, no. 4, pp. 366-372, 2006.

[65] E. Harja, L. G. Bucciarelli, Y. Lu et al., "Early growth response1 promotes atherogenesis: mice deficient in early growth response-1 and apolipoprotein E display decreased atherosclerosis and vascular inflammation," Circulation Research, vol. 94, no. 3, pp. 333-339, 2004.

[66] N. Hamada, M. Miyata, H. Eto et al., "Loss of clusterin limits atherosclerosis in apolipoprotein E-deficient mice via reduced expression of Egr-1 and TNF- $\alpha$," Journal of Atherosclerosis and Thrombosis, vol. 18, no. 3, pp. 209-216, 2010.

[67] L. M. Khachigian, V. Lindner, A. J. Williams, and T. Collins, "Egr-1-induced endothelial gene expression: a common theme in vascular injury," Science, vol. 271, no. 5254, pp. 1427-1431, 1996.

[68] E. S. Silverman, L. M. Khachigian, V. Lindner, A. J. Williams, and T. Collins, "Inducible PDGF A-chain transcription in smooth muscle cells is mediated by Egr-1 displacement of Sp1 and Sp3," American Journal of Physiology, vol. 273, no. 3, pp. H1415-H1426, 1997.

[69] E. Biesiada, M. Razandi, and E. R. Levin, "Egr-1 activates basic fibroblast growth factor transcription. Mechanistic implications for astrocyte proliferation," Journal of Biological Chemistry, vol. 271, no. 31, pp. 18576-18581, 1996.

[70] S. Ling, A. Dai, Y. H. Ma, K. Chatterjee, H. E. Ives, and K. Sudhir, "Matrix-dependent gene expression of Egr-1 and PDGF A regulate angiotensin II-induced proliferation in human vascular smooth muscle cells," Hypertension, vol. 34, no. 5, pp. 1141-1146, 1999.

[71] N. Jin, N. D. Hatton, M. A. Harrington, X. Xia, S. H. Larsen, and R. A. Rhoades, " $\mathrm{H}(2) \mathrm{O}(2)$-induced egr-1, fra-1, and cjun gene expression is mediated by tyrosine kinase in aortic smooth muscle cells," Free Radical Biology and Medicine, vol. 29, no. 8, pp. 736-746, 2000.

[72] N. Auge, N. Santanam, N. Mori, C. Keshava, and S. Parthasarathy, "Uptake of 13-hydroperoxylinoleic acid by cultured cells," Arteriosclerosis, Thrombosis, and Vascular Biology, vol. 19, no. 4, pp. 925-931, 1999.

[73] E. Blessing, M. Preusch, R. Kranzhofer et al., "Antiatherosclerotic properties of telmisartan in advanced atherosclerotic lesions in apolipoprotein E deficient mice," Atherosclerosis, vol. 199, no. 2, pp. 295-303, 2008.

[74] R. S. Chapkin, M. Young Hong, Y. Y. Fan et al., "Dietary n-3 PUFA alter colonocyte mitochondrial membrane composition and function," Lipids, vol. 37, no. 2, pp. 193-199, 2002.

[75] S. S. Dadras, S. S. Thorgeirsson, M. S. Rao, and J. K. Reddy, "Implication of hydrogen peroxide generation and apoptosis in the neoplastic transformation of mouse fibroblasts overexpressing peroxisomal fatty acyl-CoA oxidase," International Journal of Oncology, vol. 12, no. 1, pp. 37-44, 1998.

[76] V. N. Bochkov, D. Mechtcheriakova, M. Lucerna et al., "Oxidized phospholipids stimulate tissue factor expression in human endothelial cells via activation of ERK/EGR-1 and Ca++/NFAT," Blood, vol. 99, no. 1, pp. 199-206, 2002.

[77] J. J. Chiu, B. S. Wung, H. J. Hsieh, L. W. Lo, and D. L. Wang, "Nitric oxide regulates shear stress-induced early growth response-1: expression via the extracellular signal-regulated kinase pathway in endothelial cells," Circulation Research, vol. 85, no. 3, pp. 238-246, 1999.

[78] V. A. Folcik, R. A. Nivar-Aristy, L. P. Krajewski, and M. K. Cathcart, "Lipoxygenase contributes to the oxidation of lipids in human atherosclerotic plaques," Journal of Clinical Investigation, vol. 96, no. 1, pp. 504-510, 1995.

[79] K. Uchida, "Lipid peroxidation and redox-sensitive signaling pathways," Current Atherosclerosis Reports, vol. 9, no. 3, pp. 216-221, 2007. 


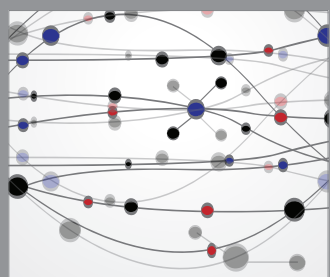

The Scientific World Journal
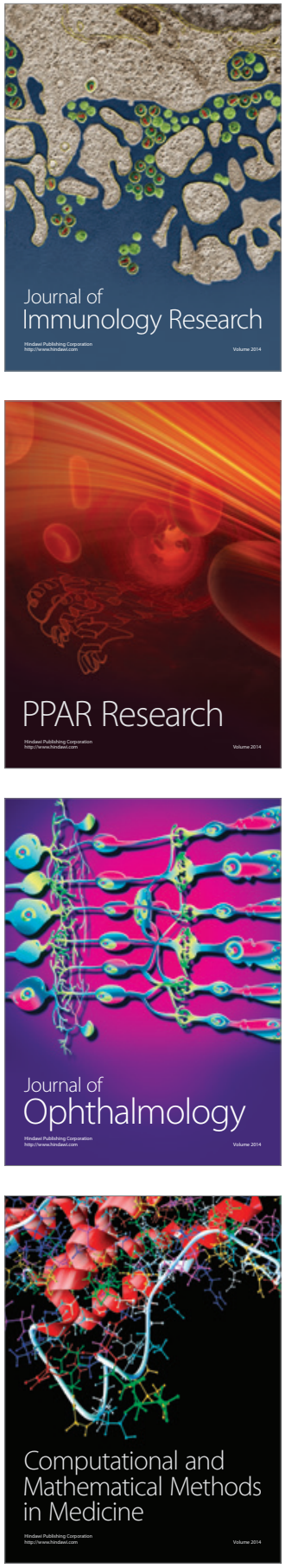

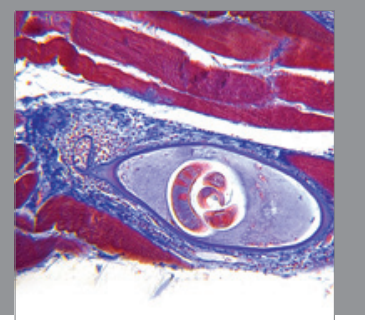

Gastroenterology

Research and Practice
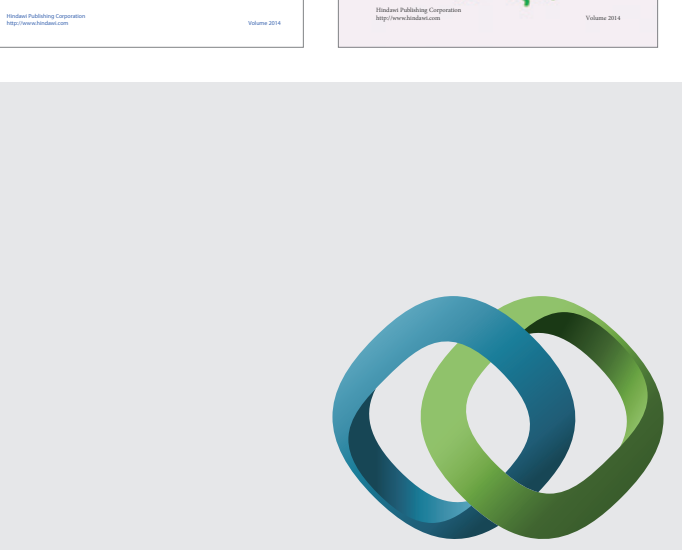

\section{Hindawi}

Submit your manuscripts at

http://www.hindawi.com
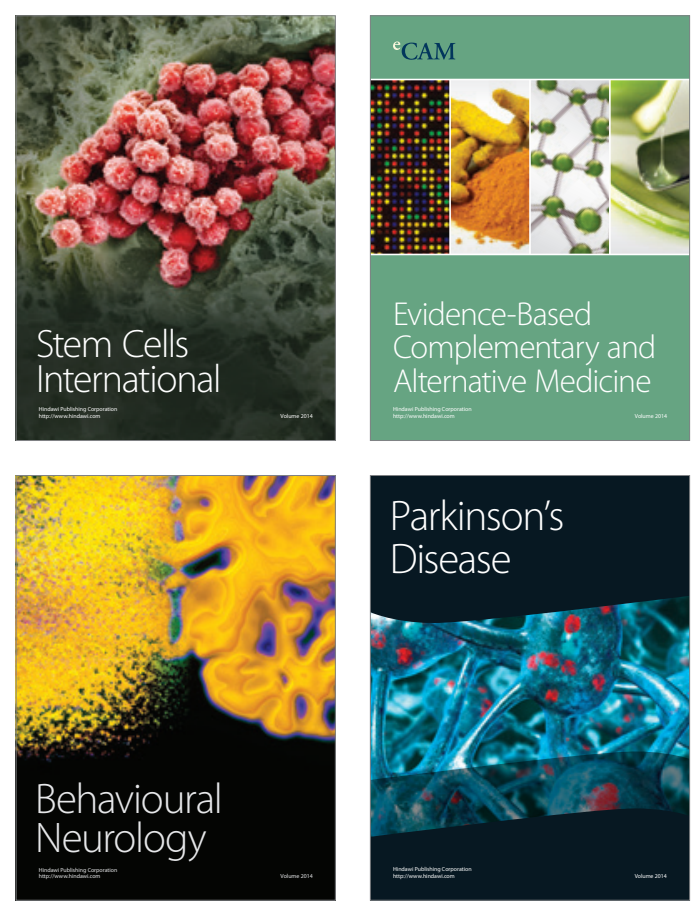

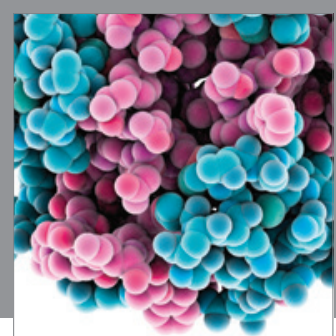

Journal of
Diabetes Research

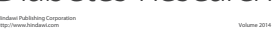

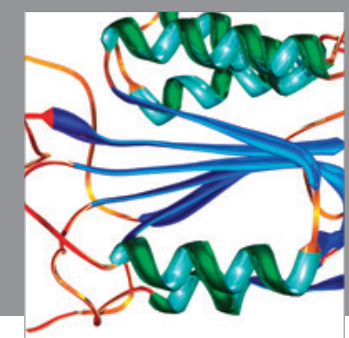

Disease Markers
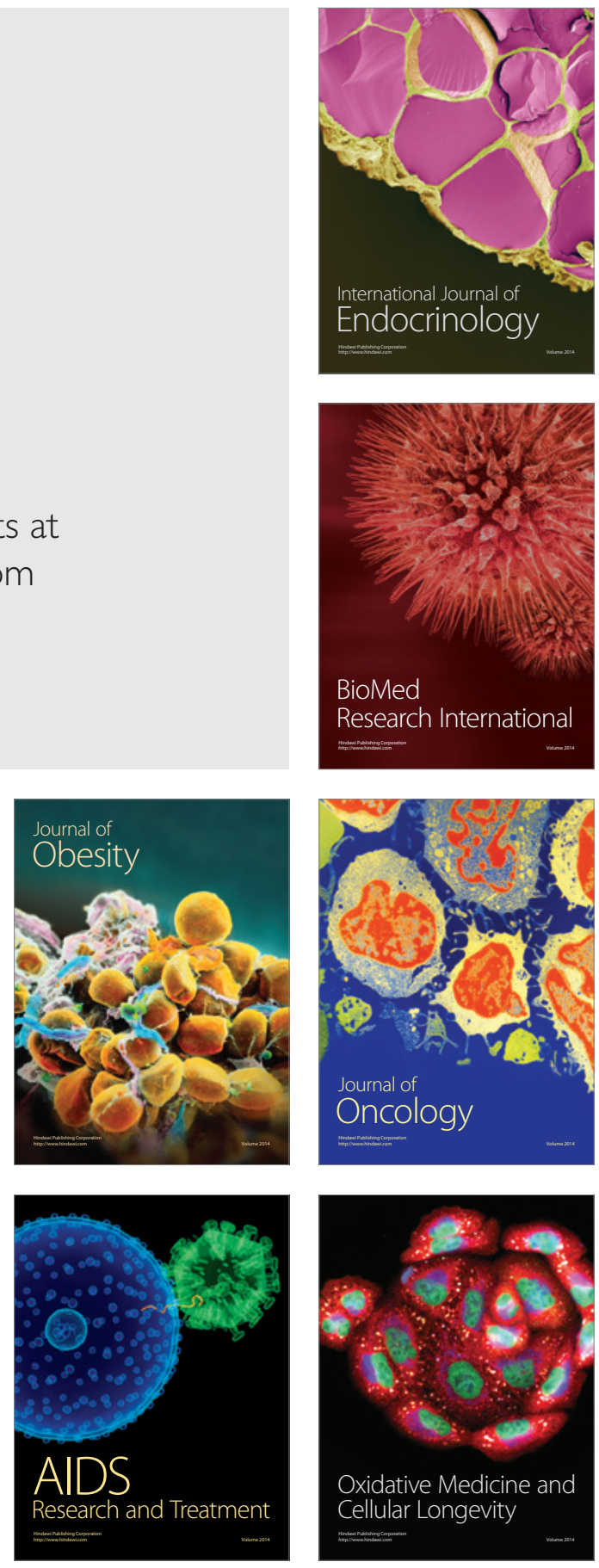